\title{
Oxidation of sulfonamide antibiotics by chlorine dioxide in water: Kinetics and reaction pathways
}

\author{
Weiwei Ben ${ }^{\mathrm{a}}$, Yanwei Shi ${ }^{\mathrm{b}, \mathrm{c}}$, Weiwei Li ${ }^{\mathrm{d}}$, Yu Zhang ${ }^{\mathrm{a}}$, Zhimin Qiang ${ }^{\mathrm{a}, *}$ \\ ${ }^{a}$ Key Laboratory of Drinking Water Science and Technology, Research Center for Eco-Environmental Sciences, University of Chinese Academy of Sciences, Chinese Academy of \\ Sciences, 18 Shuang-qing Road, Beijing 100085, China \\ ${ }^{\mathrm{b}}$ Beijing Enterprises Water Group of China Co., Ltd., 101 Baiziwan, Beijing 100124, China \\ c Beijing Engineering Research Center of Reclaimed Water Quality Security Guarantee, 101 Baiziwan, Beijing 100124, China \\ ${ }^{\mathrm{d}}$ PKU UES-Techand Ecology Joint Research and Development Center, 5 Yiheyuan Road, Beijing 100871, China
}

\section{H I G H L I G H T S}

- Sulfonamides (SAs) were effectively oxidized by $\mathrm{ClO}_{2}$ following secondorder kinetics.

- The reactivity of SAs with $\mathrm{ClO}_{2}$ showed a strong dependence on $\mathrm{pH}$ and temperature.

- Breakage of $\mathrm{S}-\mathrm{N}$ and $\mathrm{C}-\mathrm{S}$ bonds and hydroxylation of aniline group induced SAs removal.

- Antibacterial functional moieties of

SAs were disrupted by $\mathrm{ClO}_{2}$.

- Effective removal of SAs can be expected under practical water treatment conditions.

\section{A R T I C L E I N F O}

\section{Article history:}

Received 25 January 2017

Received in revised form 25 June 2017

Accepted 26 June 2017

Available online 28 June 2017

\section{Keywords:}

Sulfonamides

Chlorine dioxide

Kinetics

Reaction pathways

Water treatment

\section{G R A P H I C A L A B S T R A C T}

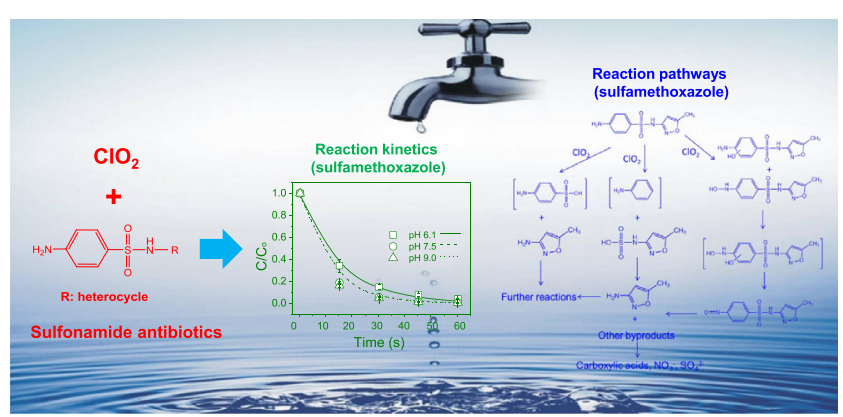

\begin{abstract}
A B S T R A C T
Sulfonamides (SAs), commonly used as human and veterinary antibiotics, are of great concerns because of their frequent detections in aquatic environment. This study investigated the oxidation of six SAs (i.e., sulfamethoxazole (SMX), sulfamethizole, sulfamethazine, sulfadimethoxine, sulfamerazine, and sulfathiazole) by chlorine dioxide $\left(\mathrm{ClO}_{2}\right)$. The results indicate that the reactions followed the second-order kinetic model, with rate constants ranging from $3.85 \times 10^{3}$ to $2.59 \times 10^{4} \mathrm{M}^{-1} \mathrm{~s}^{-1}$ at $\mathrm{pH} 7.0$ and $20^{\circ} \mathrm{C}$. For each $\mathrm{SA}$, the rate constant increased by 1.6-2.2 orders of magnitude as the solution $\mathrm{pH}$ increased from 4.0 to 9.5. The activation energies of the selected SAs ranged from 31.6 to $39.8 \mathrm{~kJ} \mathrm{~mol}^{-1}$. In addition, SMX was selected as a model compound to explore the degradation pathways during $\mathrm{ClO}_{2}$ oxidation. The reactivity of SMX toward $\mathrm{ClO}_{2}$ was strongly related to the ionization equilibrium of the amido-nitrogen in SMX molecule. The cleavage of $\mathrm{S}-\mathrm{N}$ and $\mathrm{C}-\mathrm{S}$ bonds and the hydroxylation of aniline moiety in the SMX molecule constituted the major degradation pathways. $\mathrm{ClO}_{2}$ oxidation was likely to decrease the antibacterial activity of SMX solution because of the destruction of $p$-aminobenzenesulfonamide moiety. The obtained rate constants could well predict the fate of $\mathrm{SAs}$ during $\mathrm{ClO}_{2}$ oxidation in a surface water, where an effective removal of $\mathrm{SAs}_{\text {by }} \mathrm{ClO}_{2}$ can be expected under practical water treatment conditions.
\end{abstract}

(c) 2017 Elsevier B.V. All rights reserved.

\footnotetext{
* Corresponding author.

E-mail address: qiangz@rcees.ac.cn (Z. Qiang).
}

\section{Introduction}

Antibiotics in the environment have attracted intensive concerns due to the possibility of inducing the proliferation of resistant bacterial strains. Moreover, antibiotics may also pose other 
risks to ecosystems, such as causing toxic effects on aquatic species and affecting plant growth [1]. As an important antibiotic class, sulfonamides (SAs) are extensively used in human and animal medical practices. Because of their stable chemical property and high environmental mobility [2,3], SAs have been frequently detected in a variety of aqueous media, such as effluents of wastewater treatment plants, surface water and even drinking water [4-6].

In previous studies, various chemical and photo-catalytic oxidation processes have been applied to oxidize SAs in water, such as free chlorine, ozone, ferrate $(\mathrm{Fe}(\mathrm{VI}))$ and $\mathrm{TiO}_{2}$ photocatalytic treatments [7-12], and fast reactions were generally observed. However, SAs can only be partly removed in practical ozonation and free chlorine disinfection units $[6,13]$, while ferrate and photocatalytic oxidations have not been practically applied in water treatment plants. Hence, further studies on SAs removal by other water oxidants/disinfectants are still necessary.

Chlorine dioxide $\left(\mathrm{ClO}_{2}\right)$, a commonly-applied water disinfectant, shows a higher disinfection efficiency, less $\mathrm{pH}$ dependence, and less formation of disinfection byproducts than free chlorine. Many studies have been conducted on the reactions between $\mathrm{ClO}_{2}$ and micro-pollutants in water, such as methiocarb [14], phenylurea herbicides [15], $\beta$-lactams [16], fluoroquinolones [17] and tetracyclines [18]. With regard to SAs, an appreciable reactivity of $\mathrm{ClO}_{2}$ with sulfamethoxazole (SMX) has been reported in water treatment [19]. However, the reaction kinetics and degradation pathways of other SAs during $\mathrm{ClO}_{2}$ oxidation still remain unclear.

Hence, in this study, the reaction kinetics of six SAs (i.e., SMX, sulfamethizole (SML), sulfamethazine (SMN), sulfadimethoxine (SDM), sulfamerazine (SMR), and sulfathiazole (STZ)) with $\mathrm{ClO}_{2}$ were individually determined at different $\mathrm{pHs}$ and temperatures. Thereafter, SMX was selected as a model compound to clarify the degradation pathways. The reaction kinetics of two substructural compounds of SMX, namely, 3-amino-5-methylisozazole (AMI) and 4-aminophenyl methyl sulfone (APMS), with $\mathrm{ClO}_{2}$ were determined and the oxidation byproducts of SMX were identified. Finally, the applicability of obtained rate constants to surface water was assessed.

\section{Materials and methods}

\subsection{Chemicals}

The chemical structures of SAs, AMI and APMS are shown in Fig. S1, and their corresponding standards were purchased from Sigma-Aldrich (St. Louis, USA) with purities of $>98 \%$. Methanol, acetonitrile and formic acid of high performance liquid chromatography grade were obtained from Fisher Scientific (Pittsburgh, USA). The stock solutions of SAs, AMI and APMS were prepared individually in methanol at a concentration of $100 \mathrm{mg} \mathrm{L}^{-1}$. To identify the oxidation byproducts of SMX, a stock solution of about $1000 \mathrm{mg} \mathrm{L}^{-1}$ was purposely prepared in water by adding $\mathrm{HCl}$. $\mathrm{ClO}_{2}$ stock solution ( $350 \mathrm{mg} \mathrm{L}^{-1}$ ) was prepared according to our previous work [14] and stored in brown bottles at $4{ }^{\circ} \mathrm{C}$. All other reagents used (e.g., buffers, reductant sulfite, carboxylic acids, sulfate, nitrate) were of at least analytical grade quality. High purity Milli-Q water (resistivity of $>18 \mathrm{M} \Omega \cdot \mathrm{cm}$ ) was used to prepare the aqueous solutions.

\subsection{Experimental procedures}

The reaction kinetics of SAs, AMI and APMS with $\mathrm{ClO}_{2}$ were individually examined with at least 10 -fold excess of $\mathrm{ClO}_{2}$ (5$12.5 \mu \mathrm{M}$ ), where the $\mathrm{ClO}_{2}$ concentration could be considered as constant over the reaction course and the pseudo-first-order rate constant of a target compound could be determined experimentally. The effect of $\mathrm{pH}$ on SAs degradation was investigated in a $\mathrm{pH}$ range of 4.0-9.5 with $10 \mathrm{mM}$ acetate ( $\mathrm{pH} 4.0-5.0)$, phosphate ( $\mathrm{pH}$ 6.0-8.0) and borate buffer $(\mathrm{pH}>8.0)$. The effect of temperature was tested from 5 to $34{ }^{\circ} \mathrm{C}$. The reaction was initiated by adding a desired amount of $\mathrm{ClO}_{2}$ stock solution into $20 \mathrm{~mL}$ of a buffered solution containing a target compound $(0.5 \mu \mathrm{M})$ under magnetic stirring. Water samples ( $1 \mathrm{~mL}$ each) were withdrawn at preselected time intervals and the residual oxidant was quenched immediately with excess sodium thiosulfate.

To identify the oxidation byproducts of SMX reacting with $\mathrm{ClO}_{2}$, the initial molar ratios $\left(\left[\mathrm{ClO}_{2}\right]_{\mathrm{o}} /[\mathrm{SMX}]_{\mathrm{o}}\right)$ of $1: 1$ and $4: 1$ were used and the SMX solution was prepared with an initial concentration of $40 \mu \mathrm{M}$ (i.e., about $1000 \mathrm{mg} \mathrm{L}^{-1}$ ) at $\mathrm{pH}$ 7.5. After reaction for $1 \mathrm{~h}$, water samples were taken for byproduct identification.

Degradation experiments of all selected $\mathrm{SAs}$ by $\mathrm{ClO}_{2}$ were also carried out in a filtered surface water collected from Jingmi Trench in Beijing. The main characteristics of the filtered surface water were as follows: $\mathrm{pH} 7.8$, dissolved organic carbon $4.8 \mathrm{mg} \mathrm{L}^{-1}$, $\mathrm{UV}_{254} 0.031 \mathrm{~cm}^{-1}$, and alkalinity $1.8 \mathrm{mM}$. The filtered water was buffered with $5 \mathrm{mM}$ phosphate and then spiked with each selected SA individually. The prepared reaction solutions were subject to $\mathrm{ClO}_{2}$ oxidation with an initial dosage of $1.0 \mathrm{mg} \mathrm{L}^{-1}$, which is typically applied for water disinfection. All kinetic experiments were conducted in triplicate.

\subsection{Analytical methods}

$\mathrm{ClO}_{2}$ concentration was measured with Hach method 10126 at $530 \mathrm{~nm}$ on a DR 5000 UV-Vis spectrophotometer (Hach, Loveland, USA). The concentrations of SAs, AMI and APMS were analyzed by an ultra-performance liquid chromatography tandem mass spectrometry (UPLC-MS/MS, Agilent 6240, USA) equipped with an Agilent SB-C18 column $(2.1 \times 150 \mathrm{~mm}, 1.8 \mu \mathrm{m})$. The mobile phases consisted of an aqueous solution of formic acid $(0.2 \%, \mathrm{v} / \mathrm{v})$ and acetonitrile with a total flow rate of $0.3 \mathrm{~mL} \mathrm{~min}^{-1}$, whose gradient ratio varied from 65:35 to 80:20 depending on different target compounds. The MS parameters were set as follows: capillary $4000 \mathrm{~V}$, nebulizer $35 \mathrm{psi}$, drying gas $10 \mathrm{~L} \mathrm{~min}^{-1}$, gas temperature $350^{\circ} \mathrm{C}$, and fragmentor $90-115 \mathrm{~V}$. The limits of quantification for SMX, SML, SDM, SMN, SMR and STZ were determined to be 0.8 , $1.7,1.1,1.0,1.1$ and $0.5 \mu \mathrm{g} \mathrm{L}{ }^{-1}$, respectively.

Oxidation byproducts of SMX were identified by an ultraperformance liquid chromatography/hybrid quadrupole time-offlight mass spectrometry (UPLC-Q/Tof-MS, AcQuity UPLC/Xevo G2 Q-Tof, Waters, USA) with an Eclipse plus C-18 column $(2.1 \times 150$ $\mathrm{mm}, 3.5 \mu \mathrm{m})$. Mobile phases A and B were formic acid aqueous solution $(0.2 \%, \mathrm{v} / \mathrm{v})$ and acetonitrile, respectively. The gradient program with a total flow rate of $0.3 \mathrm{~mL} \mathrm{~min}{ }^{-1}$ was set as follows ( $t$ (min), A (\%)): (0-4, 5), (4-10, 75), and (10-14, 5). The MS parameters were as follows: capillary $3000 \mathrm{~V}$, source temperature $100^{\circ} \mathrm{C}$, desolvation temperature $250{ }^{\circ} \mathrm{C}$, cone gas $50 \mathrm{~L} \mathrm{~h}^{-1}$, desolvation gas $600 \mathrm{~L} \mathrm{~h}^{-1}$, cone voltage $40 \mathrm{~V}$, and collision energy $6 \mathrm{~V}$. The MS spectra were acquired over an $m / z$ range of 50-400. Carboxylic acids, sulfate and nitrate were analyzed with an ion chromatograph (IC, ICS-2000, Dionex, USA) equipped with an IonPac AS19 column $(4 \times 250 \mathrm{~mm})$.

\section{Results and discussion}

\subsection{Determination of reaction order}

For the reaction of $\mathrm{ClO}_{2}$ with an organic pollutant, first-order kinetics was generally observed with respect to each reactant $[14,20]$. Fig. 1a shows a logarithmic representation of the kinetic 

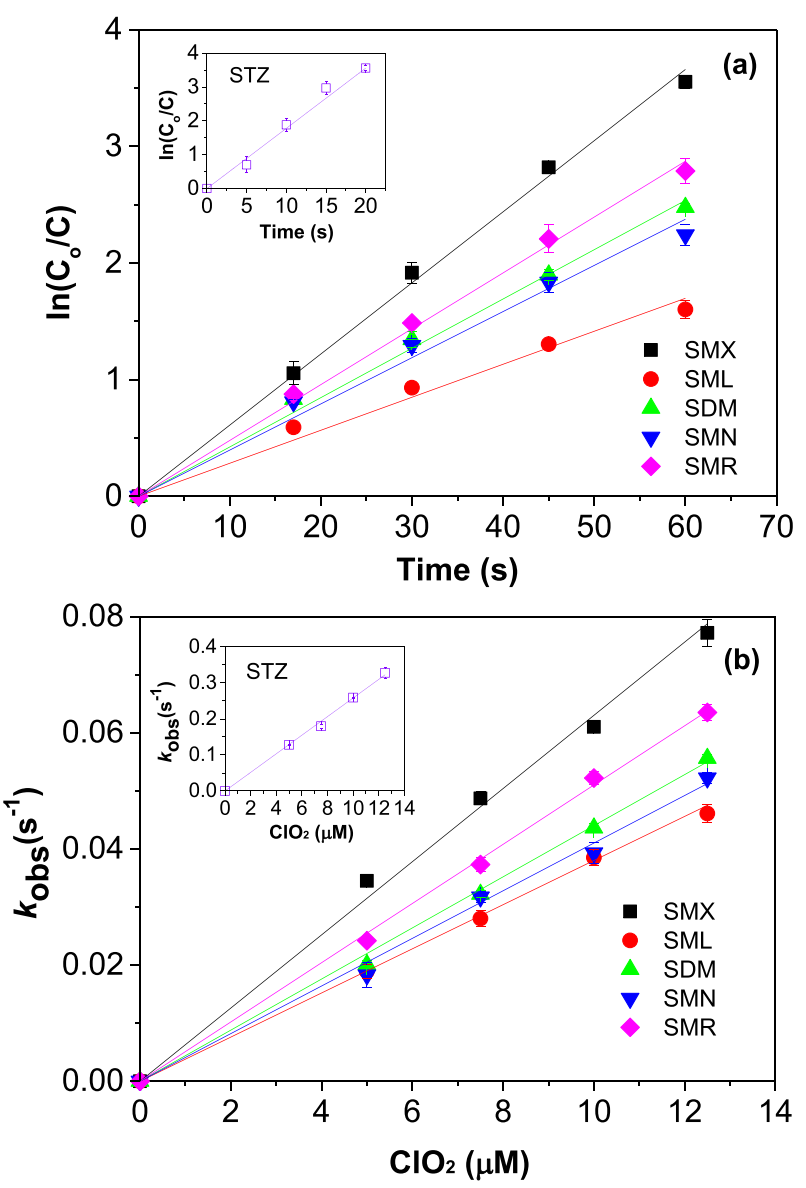

Fig. 1. Determination of the reaction order for $\mathrm{SAs}$ degradation by $\mathrm{ClO}_{2}$ : (a) plot of $\ln \left(\mathrm{C}_{\mathrm{o}} / \mathrm{C}\right)$ vs. reaction time; and (b) plot of $k_{\mathrm{obs}}$ vs. $\left[\mathrm{ClO}_{2}\right]_{\mathrm{o}}$. The reaction kinetics of STZ with $\mathrm{ClO}_{2}$ is individually shown in the insets. Experimental conditions: $[\mathrm{SA}]_{\mathrm{o}}=0.5$ $\mu \mathrm{M}, \mathrm{pH}=7.0, \mathrm{~T}=20^{\circ} \mathrm{C}$. Error bars denote the standard deviation of triplicate experiments.

data, which exhibit a good linearity $\left(\mathrm{R}^{2}>0.97\right)$ indicating the validity of the pseudo-first-order kinetic model. Fig. 1b shows that the measured pseudo-first-order reaction rate constant of each SA $\left(k_{\text {obs }}\right)$ increased linearly $\left(\mathrm{R}^{2}>0.94\right)$ with increasing $\mathrm{ClO}_{2}$ concentration, implying that the reactions were also of first-order with respect to $\mathrm{ClO}_{2}$. Thus, the overall reaction followed the secondorder kinetic model as follows:

$\frac{d[\mathrm{SA}]}{d t}=-k^{\prime \prime}[\mathrm{SA}]\left[\mathrm{ClO}_{2}\right]_{\mathrm{o}}$

$k^{\prime \prime}=\frac{k_{\mathrm{obs}}}{\left[\mathrm{ClO}_{2}\right]_{\mathrm{o}}}$

The second-order reaction rate constants $\left(k^{\prime \prime}\right)$ of SAs with $\mathrm{ClO}_{2}$ ranged from $3.85 \times 10^{3}(\mathrm{SML})$ to $2.59 \times 10^{4} \mathrm{M}^{-1} \mathrm{~s}^{-1}$ (STZ) at $\mathrm{pH} 7.0$ and
$20{ }^{\circ} \mathrm{C}$ (Table 1 ), which are generally higher than those with free chlorine $\left(10^{2}-10^{3} \mathrm{M}^{-1} \mathrm{~s}^{-1}\right)$ but lower than those with ozone $\left(10^{5}\right.$ $10^{6} \mathrm{M}^{-1} \mathrm{~s}^{-1}$ ) under comparable conditions [7,21]. Therefore, $\mathrm{ClO}_{2}$ has an appreciable reactivity toward SAs considering its relatively lower standard oxidation-reduction potential (vs. normal hydrogen electrode) at $\mathrm{pH} 7.0\left(\mathrm{ClO}_{2}, 0.935 \mathrm{~V}\right.$; free chlorine, $1.27 \mathrm{~V}$; ozone, $1.67 \mathrm{~V})[22,23]$.

\subsection{Effect of $\mathrm{pH}$}

Fig. 2 shows that the reaction rate constants of SAs with $\mathrm{ClO}_{2}$ strongly depended on the $\mathrm{pH}$. The $k^{\prime \prime}$ values increased by approximately $1.6-2.2$ orders of magnitude with increasing $\mathrm{pH}$ from 4.0 to 9.5 at $20^{\circ} \mathrm{C}$, whose large variation with $\mathrm{pH}$ could be attributed to the varying reactivity of different SA acid-base species toward $\mathrm{ClO}_{2}$. The speciation of an $\mathrm{SA}$ in aqueous solution is shown as follows:

$\mathrm{SAH}_{2}^{+} \underset{+\mathrm{H}^{+}}{\stackrel{-\mathrm{H}^{+}}{\rightleftharpoons}} \mathrm{SAH} \underset{+\mathrm{H}^{+}}{\stackrel{-\mathrm{H}^{+}}{\rightleftharpoons}} \mathrm{SA}^{-}$

The concentration of each SA can be expressed by Eq. (4):

$[\mathrm{SA}]_{\text {tot }}=\alpha_{\text {cat }}[\mathrm{SA}]_{\text {tot }}+\alpha_{\text {neu }}[\mathrm{SA}]_{\text {tot }}+\alpha_{\text {ani }}[S A]_{\text {tot }}$

where $[S A]_{\text {tot }}$ represents the total concentration of an SA; $\alpha_{\text {cat }}, \alpha_{\text {neu }}$ and $\alpha_{\text {ani }}$ are the molar fractions of the cationic $\left(\mathrm{SAH}_{2}^{+}\right)$, neutral $(\mathrm{SAH})$ and anionic $\left(\mathrm{SA}^{-}\right)$species, respectively.

As $\mathrm{ClO}_{2}$ does not change its form within the tested $\mathrm{pH}$ range, the degradation rate of SA can be expressed as follows:

$$
\begin{aligned}
\frac{d[\mathrm{SA}]_{\text {tot }}}{d t} & =-k^{\prime \prime}[\mathrm{SA}]_{\text {tot }}\left[\mathrm{ClO}_{2}\right]_{\mathrm{o}} \\
& =-\left(k_{\mathrm{cat}} \alpha_{\mathrm{cat}}[\mathrm{SA}]_{\text {tot }}+k_{\text {neu }} \alpha_{\text {neu }}[\mathrm{SA}]_{\text {tot }}+k_{\text {ani }} \alpha_{\text {ani }}[\mathrm{SA}]_{\text {tot }}\right)\left[\mathrm{ClO}_{2}\right]_{\mathrm{o}}
\end{aligned}
$$

Thus, one has

$k^{\prime \prime}=k_{\text {cat }} \alpha_{\text {cat }}+k_{\text {neu }} \alpha_{\text {neu }}+k_{\text {ani }} \alpha_{\text {ani }}$

where $k_{\text {cat }}, k_{\text {neu }}$ and $k_{\text {ani }}$ represent the specific second-order rate constants for the reactions of $\mathrm{ClO}_{2}$ with $\mathrm{SAH}_{2}^{+}, \mathrm{SAH}$ and $\mathrm{SA}^{-}$, respectively.

The $k_{\text {neu }}$ and $k_{\text {ani }}$ values were calculated by the least-square regression of kinetic data with Eq. (6) and are summarized in Table $1 . k_{\text {cat }}$ is not shown due to the negligible reaction between $\mathrm{SAH}_{2}^{+}$and $\mathrm{ClO}_{2}$. Kinetic modelling indicates that the contribution of SAH to the overall $k^{\prime \prime}$ was insignificant, while $\mathrm{SA}^{-}$was the most reactive $\left(k_{\mathrm{ani}}=3.78 \times 10^{3}-6.99 \times 10^{4} \mathrm{M}^{-1} \mathrm{~s}^{-1}\right)$ toward $\mathrm{ClO}_{2}$. Hence, an increase of $\mathrm{pH}$ led to a larger fraction of $\mathrm{SA}^{-}$, thus facilitating the reaction of an $\mathrm{SA}$ with $\mathrm{ClO}_{2}$. Similar trends were also observed for fluoroquinolones [17] and tetracyclines [18], indicating that the deprotonation of these antibiotics as $\mathrm{pH}$ increases considerably favors their oxidation by $\mathrm{ClO}_{2}$.

Besides the acid-base equilibria in aqueous solution, different substituent rings attached to the characteristic sulfinol group ( $-\mathrm{S}$ $\left.(=\mathrm{O})_{2}-\mathrm{NH}-\right)$ of SAs could also influence their reactivity toward

Table 1

\begin{tabular}{|c|c|c|c|c|c|}
\hline Compound & $\mathrm{p} K_{\mathrm{a}, 1}^{\mathrm{a}}$ & $\mathrm{p} K_{\mathrm{a}, 2}{ }^{\mathrm{a}}$ & $k_{\text {neu }}\left(\mathrm{M}^{-1} \mathrm{~s}^{-1}\right)$ & $k_{\text {ani }}\left(\mathrm{M}^{-1} \mathrm{~s}^{-1}\right)$ & $k^{\prime \prime}\left(\mathrm{M}^{-1} \mathrm{~s}^{-1}\right)(\mathrm{pH}=7.0)$ \\
\hline SMX & 1.85 & 5.60 & $0.48\left( \pm 0.07^{\mathrm{b}}\right) \times 10^{2}$ & $6.47\left( \pm 0.15^{\mathrm{b}}\right) \times 10^{3}$ & $6.13\left( \pm 0.12^{\mathrm{b}}\right) \times 10^{3}$ \\
\hline SML & 1.86 & 5.29 & $0.90( \pm 0.02) \times 10^{2}$ & $3.78( \pm 0.14) \times 10^{3}$ & $3.85( \pm 0.07) \times 10^{3}$ \\
\hline SDM & 2.13 & 6.08 & $0.35( \pm 0.14) \times 10^{2}$ & $5.33( \pm 0.14) \times 10^{3}$ & $4.36( \pm 0.10) \times 10^{3}$ \\
\hline SMN & 2.07 & 7.49 & $9.45( \pm 1.95) \times 10^{2}$ & $1.18( \pm 0.02) \times 10^{4}$ & $4.13( \pm 0.19) \times 10^{3}$ \\
\hline SMR & 2.06 & 6.90 & $9.39( \pm 2.17) \times 10^{2}$ & $8.88( \pm 0.21) \times 10^{3}$ & $5.61( \pm 0.22) \times 10^{3}$ \\
\hline STZ & 2.01 & 7.11 & $9.86( \pm 1.07) \times 10^{2}$ & $6.99( \pm 0.12) \times 10^{4}$ & $2.59( \pm 0.06) \times 10^{4}$ \\
\hline
\end{tabular}

Dissociation constants $\left(\mathrm{p} K_{\mathrm{a}}\right.$ ) of SAs and specific second-order rate constants of different SA species reacting with $\mathrm{ClO}_{2}$.

a From Ref. [30].

b Standard deviation of triplicate experiments. 

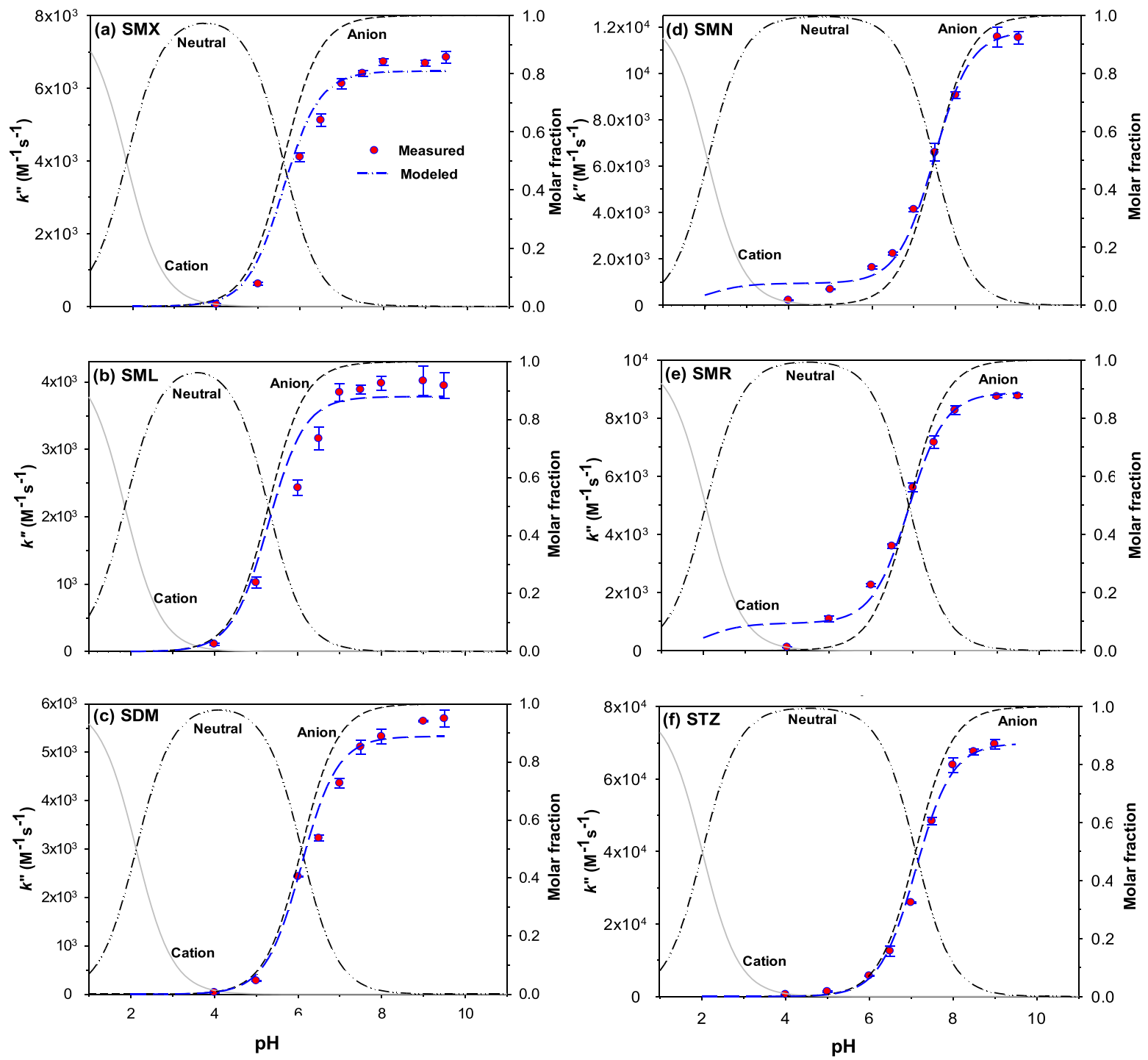

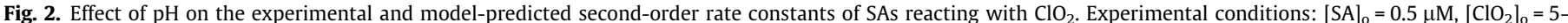
$12.5 \mu \mathrm{M}, \mathrm{T}=20^{\circ} \mathrm{C}$. Error bars denote the standard deviation of triplicate experiments.

$\mathrm{ClO}_{2}$. A more electron-withdrawing substituent ring tended to lower the $\mathrm{p} K_{\mathrm{a}, 2}$ of an SA (as is the case for SMX, SML and SDM, with a maximum $\mathrm{p} K_{\mathrm{a}, 2}$ of 6.08 ), and at the same time made its oxidation by $\mathrm{ClO}_{2}$ more difficult (a lower $k_{\text {neu }}$ ) than for other SAs (i.e., SMN, SMR and STZ) (Table 1$)$. The $k_{\text {ani }}$ was much higher than the $k_{\text {neu }}$ for all SAs and not strongly dependent on the substituent ring except for STZ, which had by far the highest $k_{\text {ani }}$. A possible explanation is that besides the sulfonyl amido-nitrogen, the electronrich thiazole ring might also be attacked by $\mathrm{ClO}_{2}$. Except for $\mathrm{STZ}$, the $k^{\prime \prime}$ values falled in a relatively narrow range, which can be explained by the fact that the negative effect of an electronwithdrawing substituent on $k_{\text {neu }}$ was compensated by a higher fraction of $\mathrm{SA}^{-}$at $\mathrm{pH}$ 7.0.

\subsection{Effect of temperature}

The effect of temperature on the reaction rate constants of SAs with $\mathrm{ClO}_{2}$ was examined over the range of $5-34{ }^{\circ} \mathrm{C}$ at $\mathrm{pH} 7.0$. The dependence of $k^{\prime \prime}$ on the reaction temperature can be expressed by the Arrhenius equation:

$\ln \left(k^{\prime \prime}\right)=\ln (\mathrm{A})-\mathrm{E}_{\mathrm{a}} / \mathrm{RT}$

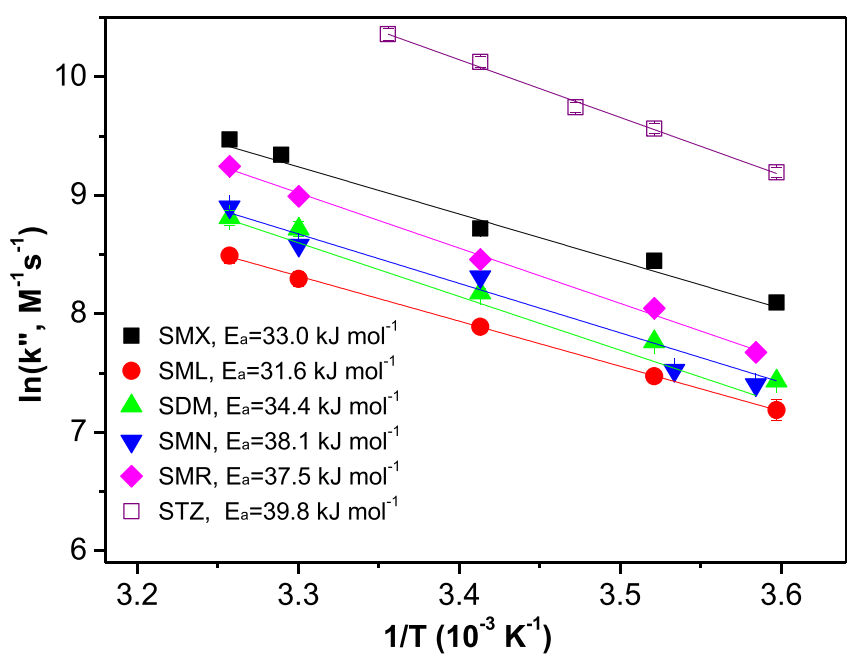

Fig. 3. Effect of temperature on the second-order rate constants of SAs reacting with $\mathrm{ClO}_{2}$. Experimental conditions: $[\mathrm{SA}]_{\mathrm{o}}=0.5 \mu \mathrm{M},\left[\mathrm{ClO}_{2}\right]_{\mathrm{o}}=5-12.5 \mu \mathrm{M}, \mathrm{pH}=7.0$. Error bars denote the standard deviation of triplicate experiments. 


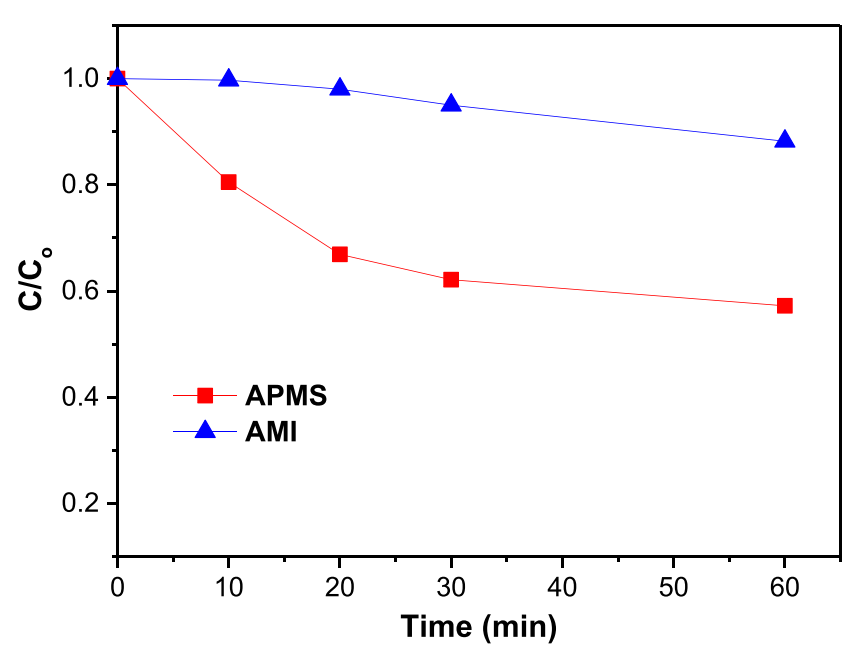

Fig. 4. Degradation of APMS and AMI by $\mathrm{ClO}_{2}$ as a function of time. Experimental conditions: $[\mathrm{AMI}]_{\mathrm{o}}=[\mathrm{APMS}]_{\mathrm{o}}=0.5 \mu \mathrm{M},\left[\mathrm{ClO}_{2}\right]_{\mathrm{o}}=12.5 \mu \mathrm{M}, \mathrm{pH}=7.0, \mathrm{~T}=20^{\circ} \mathrm{C}$.

where $\mathrm{A}=$ frequency factor, $\mathrm{E}_{\mathrm{a}}=$ activation energy, $\mathrm{R}=$ universal gas constant $\left(8.315 \mathrm{~J} \mathrm{~K}^{-1} \mathrm{~mol}^{-1}\right)$, and $\mathrm{T}=$ absolute temperature $(\mathrm{K})$.

Plotting $\ln \left(k^{\prime \prime}\right)$ vs. $1 /$ T yielded linear curves as shown in Fig. 3. The $\mathrm{E}_{\mathrm{a}}$ values were calculated to be $33.0,31.6,34.4,38.1,37.5$ and $39.8 \mathrm{~kJ} \mathrm{~mol}^{-1}$ for SMX, SML, SDM, SMN, SMR and STZ at pH 7.0 , respectively. A $10{ }^{\circ} \mathrm{C}$ temperature increase would result in an increase of $k^{\prime \prime}$ by a factor of approximately $1.56-1.75$ for the studied SAs. It is noted that an increase in temperature usually lowers the $\mathrm{p} K_{\mathrm{a}}$ of an ionizable compound [24], which causes a higher fraction of anionic species at a certain $\mathrm{pH}$ and thus enhances the reactivity toward $\mathrm{ClO}_{2}$. Hence, the temperature-dependence of $\mathrm{p} K_{\mathrm{a}}$ may also affect the $E_{a}$ values of the studied SAs.

\subsection{Reaction sites of SMX}

The reaction kinetics of two substructural compounds (i.e., AMI and APMS) of SMX with $\mathrm{ClO}_{2}$ was examined at $\mathrm{pH} 7.0$ and $20^{\circ} \mathrm{C}$ under the pseudo-first-order conditions $\left(\left[\mathrm{ClO}_{2}\right]_{\mathrm{o}} /[\mathrm{sub}-\right.$ strate $\left.]_{o}=25: 1\right)$. As shown in Fig. 4, AMI was degraded slowly, implying that the 5-methylisoxazole moiety of SMX was not a principal reaction site toward $\mathrm{ClO}_{2}$. By contrast, APMS showed a notably higher degradation rate by $\mathrm{ClO}_{2}$. On the one hand, the aniline amino-nitrogen of APMS could be directly attacked by $\mathrm{ClO}_{2}$, similar to the attacks by other oxidants such as free chlorine [8], ferrate [11] and ozone [25]. On the other hand, carboxylic acids (e.g., formic and oxalic acids), sulfate and nitrate anions were detected after the reaction of AMPS with $\mathrm{ClO}_{2}$ for $1 \mathrm{~h}$, suggesting that APMS was disrupted by $\mathrm{ClO}_{2}$ and the sulfonyl group (-S $\left.(=\mathrm{O})_{2}-\right)$ was also involved in the reactions. However, the lower reactivity of APMS toward $\mathrm{ClO}_{2}$ than SMX suggests that the sulfonyl amido-nitrogen of SMX could be a principal reaction site toward $\mathrm{ClO}_{2}$. Moreover, the $\mathrm{pH}$ dependence of the reaction rate constants of SAs with $\mathrm{ClO}_{2}$ was directly linked to the deprotonation of sulfonyl amido-nitrogen, which also emphasizes the critical role of this moiety in $\mathrm{ClO}_{2}$ oxidation. This reaction mechanism is similar to that of SMX with free chlorine [8].

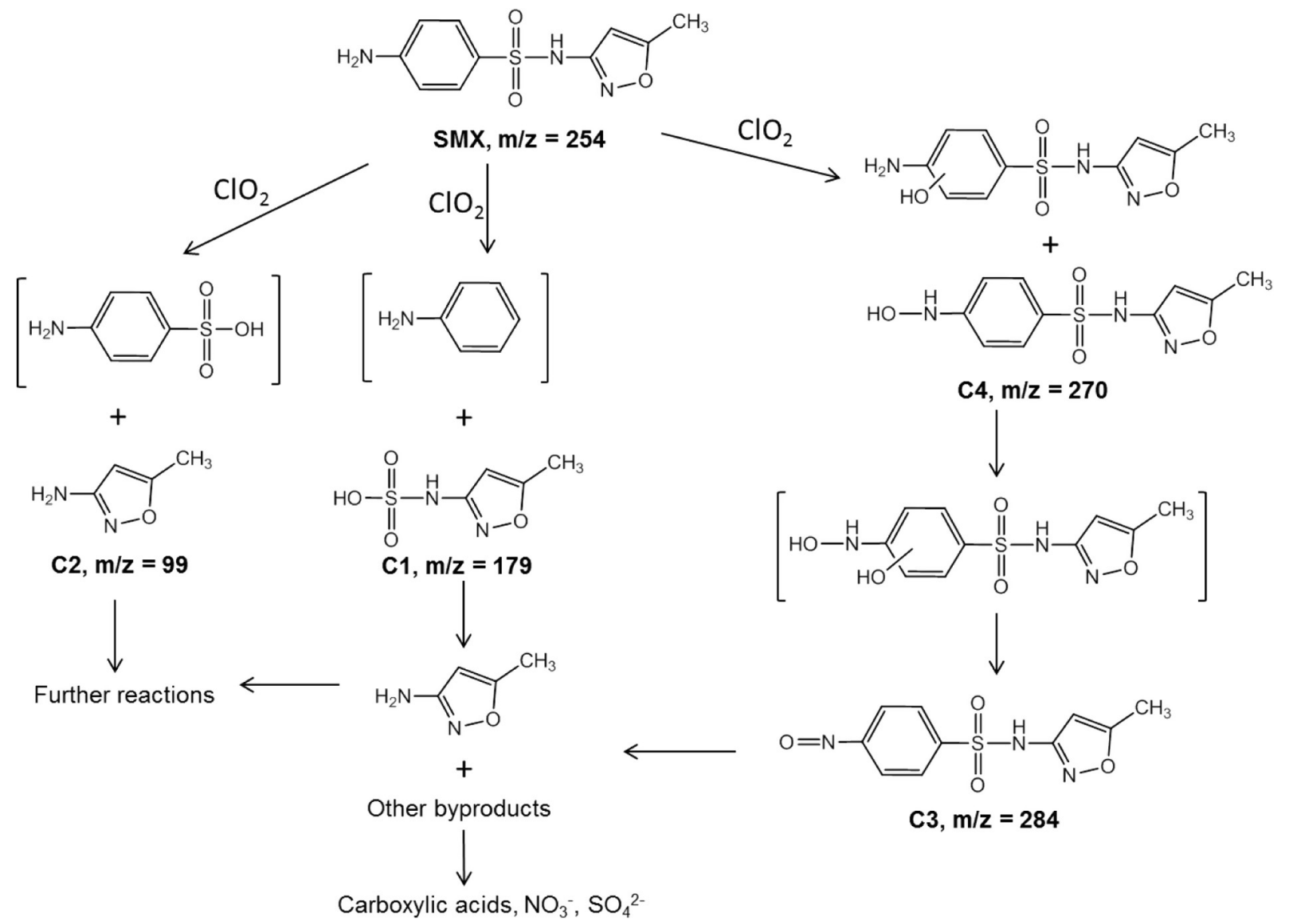

Fig. 5. Proposed degradation pathways of SMX during $\mathrm{ClO}_{2}$ oxidation. 
3.5. Identification of degradation byproducts and reaction pathways of SMX

UPLC-Q/Tof-MS was applied to identify the degradation byproducts of $\mathrm{SMX}$ by $\mathrm{ClO}_{2}$ at $\mathrm{pH}$ 7.5. The chromatograms and mass spectra of SMX and its degradation byproducts are shown in Figs. S2 and S3. The elemental composition of ion fragments was analyzed by a Tof analyzer with a high accuracy ( $<8$ ppm error). The proposed structures of degradation byproducts based on the accurate mass measurements are detailed in Table S1.

Four degradation byproducts were identified and denoted as $\mathrm{C} 1$, $\mathrm{C} 2, \mathrm{C} 3$ and $\mathrm{C} 4$, according to the eluted sequence in the chromatograms. C1, with a molecular ion of $m / z 179.0128$, could arise from the cleavage of the $\mathrm{C}-\mathrm{S}$ bond in SMX. C2, with a molecular ion of $m / z 99.0563$, was identified to be AMI, originating from the cleavage of the $\mathrm{S}-\mathrm{N}$ bond in $p$-aminobenzenesulfonamide moiety. The molecular ion of $\mathrm{C} 2$ was also observed in the fragmentation patterns of $\mathrm{C} 3, \mathrm{C} 4$ and SMX, indicating that $\mathrm{C} 3$ and $\mathrm{C} 4$ had the same 5-mehtylisoxazole moiety as SMX. No alteration of the double bond equivalents (DBE) of C4 as compared to SMX implied that C4 largely kept the original molecular structure of SMX. The molecular ion of C4 was $\mathrm{m} / \mathrm{z} 270.0566$, showing a mass gain $(+16)$ of this byproduct in comparison to SMX. Moreover, compared to the fragment ions of SMX, a mass gain of 16 commonly appeared in the C4 fragmentation ions (i.e., $\mathrm{m} / \mathrm{z}$ values of 124.0402, 172.0074, 204.0782 and 270.0556). Hence, C4 could be
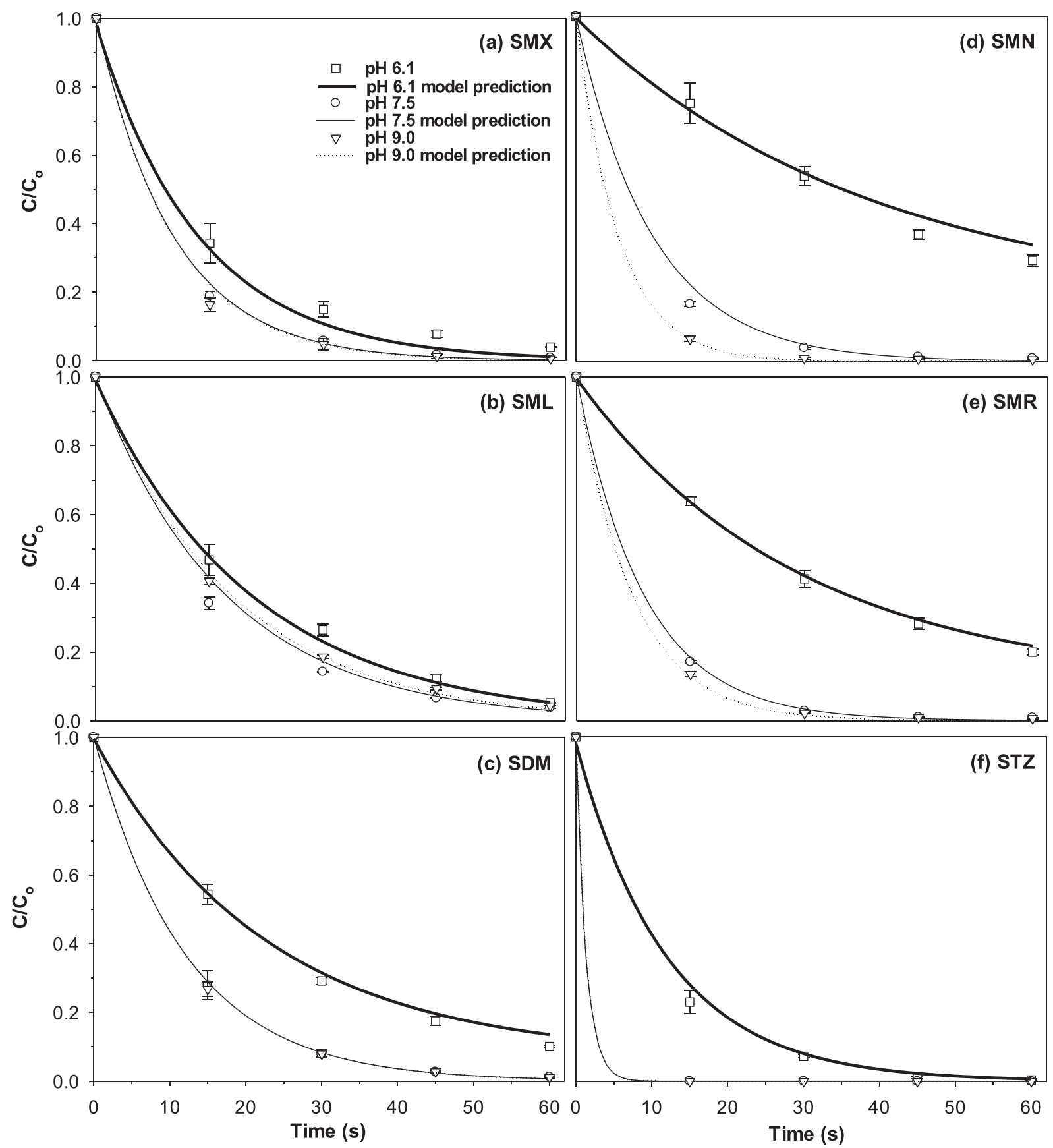

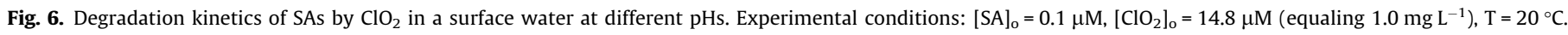
Symbols and lines represent measured data and model calculations, respectively. Error bars denote the standard deviation of triplicate experiments. 
a hydroxylated $(-\mathrm{OH})$ derivative of the aniline moiety of SMX. This byproduct was also identified from the SMX degradation by ozonation [25] and photo-Fenton oxidation [26].

The appearance of the fragment ion of $m / z$ 99.0562, absence of fragment ions of $m / z$ values of 108.0452 and 156.0120 (characteristic of the $p$-sulfoaniline ring), net mass gain of the molecular ion $(+30)$ and DBE increase (+1) of C3 compared to SMX suggested that C3 contained the 5-mehtylisoxazole moiety and oxygenation forms of the aniline group of SMX referring to the addition of $-\mathrm{OH}$ and the formation of nitroso group $(-\mathrm{N}=\mathrm{O})$. It was also reported that the amino group could be transformed to the nitroso group when SMX was oxidized by ozone [25] and ferrate [16].

When the initial molar ratio of $\left[\mathrm{ClO}_{2}\right]_{\mathrm{o}} /[\mathrm{SMX}]_{\mathrm{o}}$ increased from $1: 1$ to $4: 1$, the signal of $C 4$ disappeared while the abundance of C3 notably enhanced in the chromatogram (Fig. S2b). In addition, according to the evolution of degradation byproducts as a function of time (Fig. S4), the decay of the C4 signal was accompanied by the increase of the $\mathrm{C} 3$ signal during the reaction course. These results indicate that $\mathrm{C} 4$ could be further oxidized to $\mathrm{C} 3$ by excessive $\mathrm{ClO}_{2}$. The initial attack on the amino group of SMX probably occurred by single electron-transfer from the amino group to $\mathrm{ClO}_{2}$ [16,27]. Then, the formed aminyl radical cation evolved into a radical by $\mathrm{N}-\mathrm{H}$ deprotonation, which could couple with $\mathrm{ClO}_{2}$, oxygen or other reactive oxygen species to form hydroxylamine and hydroxylimine [16]. The hydroxylamine and hydroxylimine could be further oxidized to form the nitroso group.

Three carboxylic acids (i.e., formic, acetic and oxalic acids), and sulfate and nitrate anions were identified by IC, manifesting that the intermediates could be further oxidized. The similar observation in APMS degradation suggests that these degradation byproducts could arise from the disruption of the $p$ aminobenzenesulfonamide moiety.

Overall, the degradation pathways of SMX during $\mathrm{ClO}_{2}$ oxidation were proposed based on the degradation byproducts identified above (Fig. 5), which included: (i) $\mathrm{S}-\mathrm{N}$ bond cleavage to form $\mathrm{C} 2$ and sulfanilic acid; (ii) $\mathrm{C}-\mathrm{S}$ bond cleavage to form $\mathrm{C} 1$ and aniline; and (iii) hydroxylation of the aniline moiety to form C4 and further oxidation of the amino group attached to benzene ring to form C3. According to the evolution of degradation byproducts as a function of time, under the initial molar ratio of $\left[\mathrm{ClO}_{2}\right]_{\mathrm{o}} /$ $[\mathrm{SMX}]_{\mathrm{o}}$ of $4: 1, \mathrm{C} 1$ and $\mathrm{C} 2$ showed a rapid increase within the first $20 \mathrm{~s}$ and a continuous decrease thereafter, while C3 always showed a continuous increase (Fig. S4a). When the initial molar ratio of $\left[\mathrm{ClO}_{2}\right]_{\mathrm{o}} /[\mathrm{SMX}]_{\mathrm{o}}$ was increased to $10: 1, \mathrm{C} 3$ started to decrease after a reaction time of $10 \mathrm{~min}$ (Fig. S4b). Therefore, further disruption of $\mathrm{C} 1, \mathrm{C} 2$ and $\mathrm{C} 3$ could be expected by the oxidation of excessive $\mathrm{ClO}_{2}$, which led to the formation of carboxylic acids, and sulfate and nitrate anions. The proposed sulfanilic acid, aniline and hydroxylsubstituted C4 intermediates were not observed in the chromatograms, probably because these intermediates could be rapidly oxidized by $\mathrm{ClO}_{2}$ once formed. Chlorine substitution, an important reaction mechanism of antibiotics with free chlorine $[8,17,18]$, was not observed in any of the byproducts during the reaction of SMX with $\mathrm{ClO}_{2}$.

The antibacterial activity of SAs is derived from its antagonistic competition with $p$-aminobenzoic acid for the dihydropteroate synthase enzyme, which is necessary for bacterial folic acid synthesis $[8,11]$. Therefore, it is expected that the oxidation of the amino group, cleavage of the $\mathrm{S}-\mathrm{N}$ bond, and disruption of the $p$ aminobenzenesulfonamide moiety will render SMX less of a mimic for the $p$-aminobenzoic acid, thus reducing its antibacterial activity. Based on the structural similarities of SAs, the antibacterial activities of other studied SAs are also expected to be reduced after reaction with $\mathrm{ClO}_{2}$. However, because of the different heterocyclic types, the degradation pathways of other studied SAs during $\mathrm{ClO}_{2}$ oxidation are likely to be different from that of SMX, which requires further studies.

\subsection{Degradation of $\mathrm{SAs}$ by $\mathrm{ClO}_{2}$ in a surface water}

The effect of water matrix on the reaction kinetics of the studied SAs toward $\mathrm{ClO}_{2}$ was investigated. The SA concentrations could reach as high as $\mu \mathrm{g} \mathrm{L}^{-1}$ levels in surface water. For example, SDM, SMN and sulfapyridine were detected at concentrations of $15,6.2$ and $12 \mu \mathrm{g} \mathrm{L}^{-1}$, respectively, in surface water samples in $U$. S. and Spain $[28,29]$. Accordingly, surface water samples were spiked with $0.1 \mu \mathrm{M}$ of $\mathrm{SA}$ and exposed to $1.0 \mathrm{mg} \mathrm{L}^{-1}$ of $\mathrm{ClO}_{2}$ (14.8 $\mu \mathrm{M}$, a typical dosage in water treatment) in this study. Oxidative degradation of SAs can be predicted using Eq. (8) along with the kinetic parameters for each target SA:

$[\mathrm{SA}]=[\mathrm{SA}]_{0} \mathrm{e}^{-\left(k_{\text {cat }} \alpha_{\text {cat }}+k_{\text {neu }} \alpha_{\text {neu }}+k_{\text {ani }} \alpha_{\text {ani }}\right) \times C T}$

where $C$ is the $\mathrm{ClO}_{2}$ concentration at time $t$, and $T$ is the reaction time; so their product, $C T$, represents the integrated $\mathrm{ClO}_{2}$ exposure during water treatment. The surface water samples exhibited a noticeable consumption of $\mathrm{ClO}_{2}$, with a $13.4 \%$ decrease of $\mathrm{ClO}_{2}$ concentration after $1 \mathrm{~min}$ under the adopted experimental conditions (Fig. S5).

As shown in Fig. 6, the model predicted degradation curves of the studied SAs agreed quite well with the experimentally measured data in a surface water. The removal efficiencies of SAs reached $96-100 \%$ after a contact time of 1 min with $1.0 \mathrm{mg} \mathrm{L}^{-1}$ $\mathrm{ClO}_{2}$ at $\mathrm{pHs} 7.5$ and 9.0; while a decrease of $\mathrm{pH}$ to 6.1 retarded the removal of SAs to different degrees. Overall, a high removal of the studied SAs could be expected under typical water treatment conditions for $\mathrm{ClO}_{2}$ oxidation.

\section{Conclusions}

The reactions between six studied SAs and $\mathrm{ClO}_{2}$ in water followed the second-order kinetic model. The reaction rate constants ranged from $3.85 \times 10^{3}$ to $2.59 \times 10^{4} \mathrm{M}^{-1} \mathrm{~s}^{-1}$ (at pH 7.0 and $20^{\circ} \mathrm{C}$ ) and showed a strong $\mathrm{pH}$ dependence. The cleavage of $\mathrm{S}-\mathrm{N}$ and $\mathrm{C}-\mathrm{S}$ bonds and the hydroxylation of aniline moiety in the SMX molecule were the major degradation pathways. The degradation of SAs in a surface water could be well predicted by the kinetic parameters obtained in Milli-Q water. A high removal of SAs could be expected under typical water treatment conditions for $\mathrm{ClO}_{2}$ oxidation.

\section{Acknowledgement}

This project was financially supported by the National Natural Science Foundation of China (21590814, 51678559, 51525806), Ministry of Science and Technology of China (2012ZX07404-004) and CAS-SAFEA International Partnership Program for Creative Research Teams.

\section{Appendix A. Supplementary material}

Supplementary data associated with this article can be found, in the online version, at http://dx.doi.org/10.1016/j.cej.2017.06.157.

\section{References}

[1] A.K. Sarmah, M.T. Meyer, A.B.A. Boxall, A global perspective on the use, sales, exposure pathways, occurrence, fate and effects of veterinary antibiotics (VAs) in the environment, Chemosphere 65 (2006) 725-759.

[2] A. Dirany, I. Sirés, I., N. Oturan, A. Özcan, M.A. Oturan, Electrochemical treatment of the antibiotic sulfachloropyridazine: kinetics, reaction pathways, and toxicity evolution, Environ. Sci. Technol. 46 (2012) 4074-4082. 
[3] J.F. Lian, Z.M. Qiang, M.K. Li, J.R. Bolton, J.H. Qu, UV photolysis kinetics of sulfonamides in aqueous solution based on optimized fluence quantification, Water Res. 75 (2015) 43-50.

[4] X.J. Yuan, Z.M. Qiang, W.W. Ben, B. Zhu, J.H. Qu, Distribution, mass load and environmental impact of multiple-class pharmaceuticals in conventional and upgraded municipal wastewater treatment plants in East China, Environ. Sci. Process. Impacts 17 (2015) 596-605.

[5] M.J. García-Galán, T. Garrido, J. Fraile, A. Ginebreda, M.S. Díaz-Cruz, D. Barceló Simultaneous occurrence of nitrates and sulfonamide antibiotics in two ground water bodies of Catalonia (Spain), J. Hydrol. 383 (2010) 93-101.

[6] V.D.J. Gaffney, C.M.M. Almeida, A. Rodrigues, E. Ferreira, M.J. Benoliel, V.V. Cardoso, Occurrence of pharmaceuticals in a water supply system and related human health risk assessment, Water Res. 72 (2015) 199-208.

[7] E. Chamberlain, C. Adams, Oxidation of sulfonamides, macrolides, and carbadox with free chlorine and monochloramine, Water Res. 40 (2006) 2517-2526.

[8] M.C. Dodd, C.H. Huang, Transformation of the antibacterial agent sulfamethoxazole in reactions with chlorine: kinetics, mechanisms, and pathways, Environ. Sci. Technol. 38 (2004) 5607-5615.

[9] T. Garoma, S.K. Umamaheshwar, A. Mumper, Removal of sulfadiazine, sulfamethizole, sulfamethoxazole, and sulfathiazole from aqueous solution by ozonation, Chemosphere 79 (2010) 814-820.

[10] M.M. Huber, A. Göbel, A. Joss, N. Hermann, D. Löffler, C.S. Mcardell, A. Ried, H. Siegrist, T.A. Ternes, U. von Gunten, Oxidation of pharmaceuticals during ozonation of municipal wastewater effluents: a pilot study, Environ. Sci. Technol. 39 (2005) 4290-4299.

[11] V.K. Sharma, S.K. Mishra, N. Nesnas, Oxidation of sulfonamide antimicrobials by ferrate (VI) [( $\left.\left.\mathrm{Fe}^{\mathrm{VI}} \mathrm{O}_{4}^{2-}\right)\right]$, Environ. Sci. Technol. 40 (2006) $7222-7227$.

[12] L.H. Hu, P.M. Flanders, P.L. Miller, T.J. Strathmann, Oxidation of sulfamethoxazole and related antimicrobial agents by $\mathrm{TiO}_{2}$ photocatalysis, Water Res. 41 (2007) 2612-2626.

[13] L.P. Padhye, H. Yao, F.T. Kung'u, C.H. Huang, Year-long evaluation on the ccurrence and fate of pharmaceuticals, personal care products, and endocrine disrupting chemicals in an urban drinking water treatment plant, Water Res. 51 (2014) 266-276.

[14] F. Tian, Z.M. Qiang, C. Liu, T. Zhang, B.Z. Dong, Kinetics and mechanism for methiocarb degradation by chlorine dioxide in aqueous solution, Chemosphere 79 (2010) 646-651.

[15] F.X. Tian, B. Xu, T.Y. Zhang, N.Y. Gao, Degradation of phenylurea herbicides by chlorine dioxide and formation of disinfection by-products during subsequent chlor(am)ination, Chem. Eng. J. 258 (2014) 210-217.

[16] S. Navalon, M. Alvaro, H. Garcia, Reaction of chlorine dioxide with emergent water pollutants: product study of the reaction of three beta-lactam antibiotics with $\mathrm{ClO}_{2}$, Water Res. 42 (2008) 1935-1942.
17] P. Wang, Y.L. He, C.H. Huang, Oxidation of fluoroquinolone antibiotics and structurally related amines by chlorine dioxide: reaction kinetics, product and pathway evaluation, Water Res. 44 (2010) 5989-5998.

[18] P. Wang, Y.L. He, C.H. Huang, Reactions of tetracycline antibiotics with chlorine dioxide and free chlorine, Water Res. 45 (2011) 1838-1846.

[19] M.M. Huber, S. Korhonen, T.A. Ternes, U. von Gunten, Oxidation of pharmaceuticals during water treatment with chlorine dioxide, Water Res. 39 (2005) 3607-3617.

[20] T.P.J. Kull, P.H. Backlund, K.M. Karlsson, J.A.O. Meriluoto, Oxidation of the cyanobacterial hepatotoxin microcystin-LR by chlorine dioxide: reaction kinetics, characterization, and toxicity of reaction products, Environ. Sci. Technol. 38 (2004) 6025-6031.

[21] M.M. Huber, S. Canonica, G.Y. Park, U. Von Gunten, Oxidation of pharmaceuticals during ozonation and advanced oxidation processes, Environ. Sci. Technol. 37 (2003) 1016-1024.

[22] L.H. Hu, H.M. Martin, T.J. Strathmann, Oxidation kinetics of antibiotics during water treatment with potassium permanganate, Environ. Sci. Technol. 44 (2010) 6416-6422.

23] D.A. Armstrong, R.E. Huie, W.H. Koppenol, S.V. Lymar, G. Merényi, P. Neta, B. Ruscic, D.M. Stanbury, S. Steenken, P. Wardman, Standard electrode potentials involving radicals in aqueous solution: inorganic radicals (IUPAC technical report), Pure Appl. Chem. 87 (2015) 1139-1150.

[24] Z.M. Oiang, C. Adams, Determination of monochloramine formation rate constants with stopped-flow spectrophotometry, Environ. Sci. Technol. 38 (2004) 1435-1444.

25] M.D. Gómez-Ramos, M. Mezcua, A. Agüera, A.R. Fernández-Alba, S. Gonzalo, A. Rodríguez, R. Rosal, Chemical and toxicological evolution of the antibiotic sulfamethoxazole under ozone treatment in water solution, J. Hazard. Mater 192 (2011) 18-25.

[26] A.G. Trovó, R.F.P. Nogueira, A. Agüera, A.R. Fernandez-Alba, C. Sirtori, S. Malato, Degradation of sulfamethoxazole in water by solar photo-Fenton chemical and toxicological evaluation, Water Res. 43 (2009) 3922-3931.

[27] H. Huang, D. Sommerfeld, B.C. Dunn, C.R. Lloyd, E.M. Eyring, Ferrate(VI) oxidation of aniline, J. Chem. Soc., Dalton Trans. (2001) 1301-1305.

[28] M.E. Lindsey, M. Meyer, E.M. Thurman, Analysis of trace levels of sulfonamide and tetracycline antimicrobials in groundwater and surface water using solidphase extraction and liquid chromatography/mass spectrometry, Anal. Chem. 73 (2001) 4640-4646.

[29] M.S. Díaz-Cruz, M.J. García-Galán, D. Barceló, Highly sensitive simultaneous determination of sulfonamide antibiotics and one metabolite in environmental waters by liquid chromatography-quadrupole linear ion trap-mass spectrometry, J. Chromatogr. A 1193 (2008) 50-59.

[30] Z.M. Qiang, C. Adams, Potentiometric determination of acid dissociation constants $\left(\mathrm{pK}_{2}\right)$ for human and veterinary antibiotics, Water Res. 38 (2004) 2874-2890. 